\title{
Consolidation of magnesium and magnesium-quasicrystal composites through high-pressure torsion
}

\author{
M. M. Castro ${ }^{1}$, W. Wolf ${ }^{1}$, A. Isaac ${ }^{1}$, M. Kawasaki², R. B. Figueiredo ${ }^{\dagger, 1}$ \\ †figueiredo@demet.ufmg.br
}
${ }^{1}$ Department of Metallurgical and Materials Engineering, Universidade Federal de Minas Gerais, Belo Horizonte, 31270 - 901, Brazil
${ }^{2}$ Department of Mechanical, Industrial and Manufacturing Engineering, Oregon State University, Corvallis, $97331-6001$, U.S. A.

\begin{abstract}
It is of great interest to produce magnesium-based composites through room temperature consolidation of particles using highpressure torsion. However, the lack of bonding between the particles compromises the integrity and ductility of such materials. The present work evaluates the microstructure of the composites involving pure magnesium and a magnesium alloy AZ91 with the incorporation of quasicrystal particles as a reinforcement phase. Thus, an Al-Cu-Fe icosahedral quasicrystalline alloy was produced by gas atomization and mixed with magnesium particles in a proportion of $80 \%$ in weight of metal and $20 \%$ of quasicrystal. The mix was processed by different number of turns of high-pressure torsion. The microstructure was observed using scanning electron microscopy and the mechanical behavior was evaluated using tensile testing. Generalized lack of bonding is observed in the AZ91 alloy matrix composite and localized lack of bonding in the pure magnesium matrix. High tensile strength has been achieved after consolidation of pure magnesium with and without quasicrystal reinforcement but all samples display limited ductility. The elongations are less than $5 \%$ in all conditions. This is attributed to pre-existing areas with lack of bonding in the matrix, cracking of the hard particles and lack of bonding between the matrix and the reinforcement particles.
\end{abstract}

Keywords: magnesium, composite, severe plastic deformation, high-pressure torsion.

\section{Introduction}

Metal matrix composites (MMC) usually display the high strength, toughness and rigidity of metallic materials and incorporates a second phase which improves specific properties and the overall performance in targeted applications. For example, MMCs reinforced with ceramic phases may display improved wear resistance compared to the unreinforced metal. MMCs are usually produced by melting or sintering and these techniques involve a high temperature processing step.

Recent papers have shown that it is possible to produce MMCs, at room temperature, by consolidation of metallic particles through high-pressure torsion (HPT) [1-8]. This severe plastic deformation technique has been widely used to refine the grain structure of metallic materials $[9,10]$. Additionally, the high hydrostatic stress and high amount of shear deformation are also effective to break up the surface oxide layer of metallic particles and promote their bonding.

HPT has been used to produce magnesium-based composites with different materials to meet the performance targets. For example, it was shown that the incorporation of alumina particles into pure magnesium matrix promotes a slight increase in hardness and in room temperature creep resistance [11]. Magnesium can also be mixed with pure aluminum to produce a ductile metastable composite which can be hardened by thermal treatment [12]. Also, bioactive materials can be used to produce a bioactive magnesium- based biodegradable composite [13]. Thus, a potential to produce the magnesium-based MMCs with improved performance is apparent. However, a recent paper [13] showed that the tensile behavior of a composite of magnesium with hydroxyapatite is characterized by a high mechanical strength, however, the elongation is significantly reduced compared to pure magnesium processed by HPT [14]. The reason for this lack of ductility in the magnesiumbased composite is not clear yet. Also, the majority of reports on consolidation of magnesium-based composites are related to commercially pure magnesium as the matrix material. Despite a report of full consolidation of a Mg-Zn-Y alloy [15], recent attempts to consolidate the AZ91 alloy did not produce sound samples $[13,16]$. Thus, the present paper aims to evaluate the tensile behavior of pure magnesium and a magnesium composite consolidated through HPT and to evaluate the effectiveness in consolidation of an AZ91 magnesium alloy. An Al-Cu-Fe icosahedral quasicrystalline alloy produced by gas-atomization is used as a reinforcement phase in the magnesium-based composites. The fabrication process used here to produce quasicrystalline powders allows obtaining different particle sizes, which facilitates the mixing with the magnesium particles without significant heterogeneity in distribution of phases. Quasicrystalline phases display interesting functional properties such as low friction coefficient, low surface adhesion energy and high hardness [17], which are interesting for tribological protection [18]. These properties are associated to their 
complex atomic organization [19]. To this date, MMCs reinforced with quasicrystals have been only fabricated by thermally assisted processes, involving solidification [20,21] or hot consolidation of mechanically mixed powders [22]. In this work, we fabricate this composite by cold consolidation.

\section{Experimental procedure}

The materials used in the present experiments were commercially pure magnesium, AZ91 magnesium alloy and AlCuFe quasicrystal (QC) particles. The QC particles were fabricated by gas-atomization of commercially pure elements (purity $>99 \%$ ), with nominal atomic composition of $\mathrm{Al}_{62.5} \mathrm{Cu}_{25} \mathrm{Fe}_{12.5}$. Fig. 1 shows scanning electron microscopy images of the initial materials and the composition of the quasicrystal particles determined by energy dispersive spectroscopy (EDS), being relatively close to the nominal alloy composition. Two composite mixtures were prepared with $80 \%$ in weight of metallic particles (magnesium or the alloy) and $20 \mathrm{wt} . \%$ of quasicrystal particles. The particles were hand mixed and pressed into $10 \mathrm{~mm}$ diameter and $1 \mathrm{~mm}$ thickness green discs using a pressure of $400 \mathrm{MPa}$. Discs of $100 \%$ pure magnesium were also pressed using similar procedure. The pressed discs were processed by HPT using a quasi-constrained facility operating with a nominal pressure of $3.8 \mathrm{GPa}$. Samples were processed to 5, 10 and 20 turns at room temperature.

Processed discs were ground and polished and observed by scanning electron microscopy (SEM). Miniature tensile specimens with $1.5 \mathrm{~mm}$ gauge length and $1 \mathrm{~mm}$ width were cut from processed discs of pure magnesium and the $\mathrm{Mg}-20 \%$ QC composite. The specimens were ground and polished and the thickness of each specimen varied within the range 0.5-0.6 mm. Tensile tests were carried out using constant rate of cross-head displacement and an initial strain-rate of $10^{-4} \mathrm{~s}^{-1}$. The load and displacement data were converted to engineering stress and strain. The elastic distortion of the

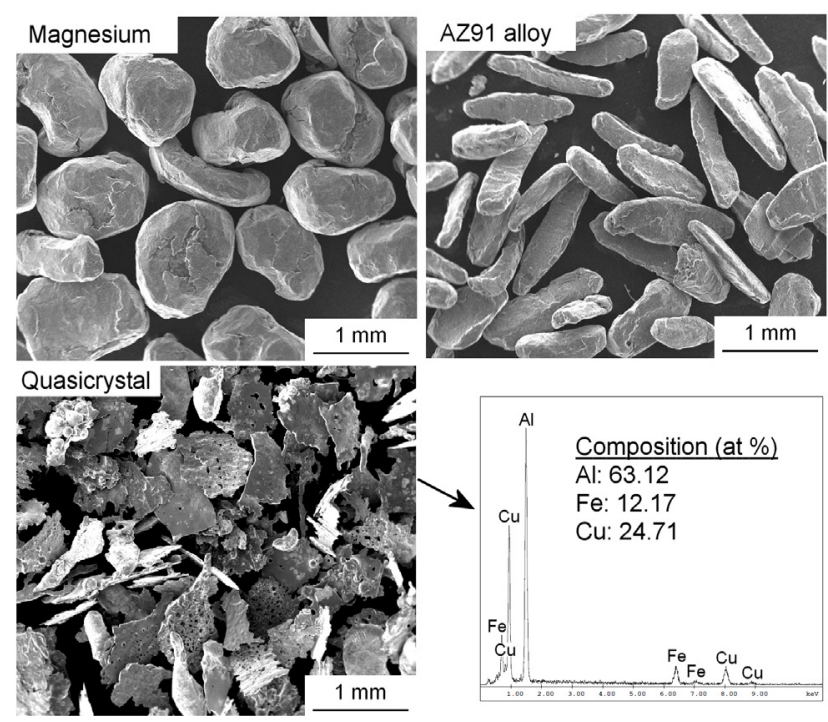

Fig. 1. SEM images of the starting materials used to produce the green discs.

tensile test apparatus was corrected by equating the elastic portion of the curves to the elastic modulus of magnesium. After testing, the specimens were observed using SEM.

\section{Experimental results}

Visual inspection of the HPT processed discs revealed an apparent effective consolidation. Careful examination of the SEM images with low to high magnifications of the Mg-20\% QC and AZ91-20\% QC composites, exhibited in Fig. 2, provides clear evidence of their partial consolidation after 10 turns of HPT at room temperature. A large amount of interparticle pores can be detected in the matrix of the AZ91-20\% QC composite, which are revealed as continuous frontiers between areas with size compatible to the original

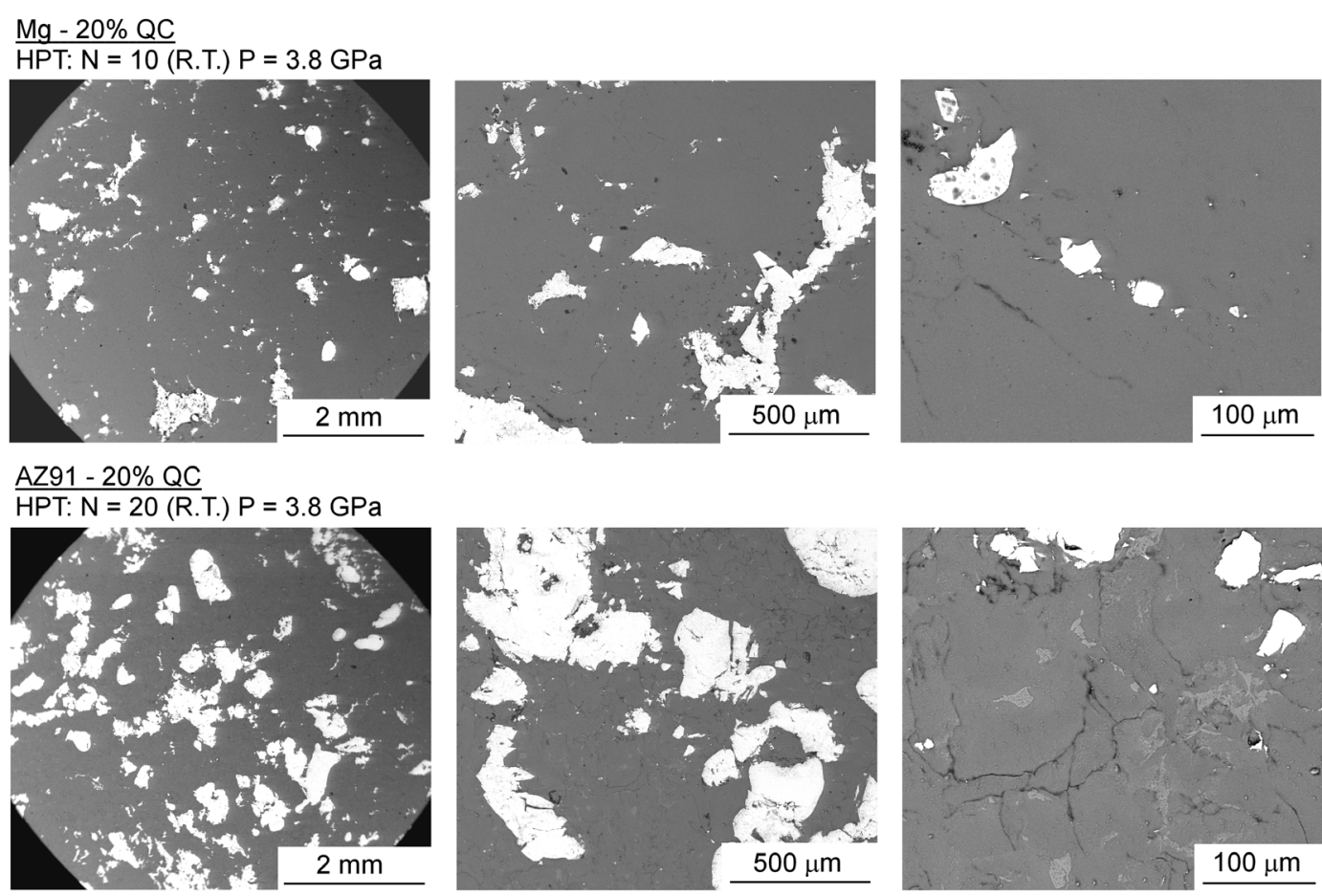

Fig. 2. Microstructure of the Mg-20\% QC and AZ91-20\% QC composites processed to 10 turns of HPT. 
particles of AZ91 (hundreds of microns). Additionally, it is observed that the QC particles are well dispersed in the metallic matrix and exhibit a bimodal size distribution. Whereas most of the QC particles is still in the range of hundreds of microns, few particles have size in the order of tens of microns as a result of the fragmentation during the HPT processing. Differently from the generalized lack of consolidation in the AZ91-20\% QC composite, the Mg-20\% QC sample displays a small amount of interparticle pores suggesting localized lack of consolidation.

Fig. 3 shows the stress vs strain curves obtained by tensile testing of pure magnesium and the Mg-20\% QC composite processed to different number of turns. Each test was repeated and the difference between the ultimate stress and final elongation was within $10 \%$ for all conditions. It is observed that the discs of pure magnesium do not display significant difference in strength and elongation with varying number of turns. Also, the flow and ultimate stresses are higher than those observed in bulk pure magnesium processed by HPT $[14,23]$. On the other hand, the elongation is significantly lower. In practice, the Mg-20\% QC composite after 5 turns of HPT displayed about $50 \%$ of the ultimate stress obtained for the pure magnesium subjected to the same processing conditions, suggesting the relatively lower level of consolidation. The strength increases significantly after 10 turns suggesting improved consolidation. However, further processing to 20 turns reduces the strength of the composite. It is worth noting that the flow curve of the composite processed by 20 turns does not display a stage of apparent hardening, which was observed in all other samples. This suggests that the material is the most brittle among all samples and the fracture at low stress can be attributed to such less strain hardening.

Both the pure magnesium and the Mg-20\% QC composite exhibit very limited ductility. The elongations were $\sim 2 \%$ only in all specimens. This is unexpectedly low for magnesium processed by HPT since the processing ofbulkpure magnesium leads to extraordinary ductility after only $1 / 2$ turn [24]. The surfaces of the tested specimens were observed in SEM and Figs. 4 and 5 show the representative images of the pure magnesium and the composite, respectively. The surfaces of the pure magnesium specimens show no evidence of plastic deformation within the gauge length which corroborates

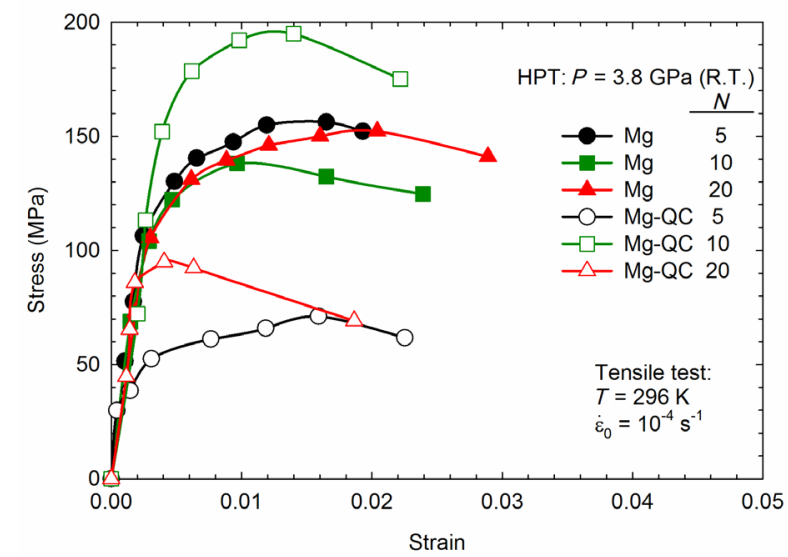

Fig. 3. (Color online) Stress vs strain curves of the pure magnesium and the Mg-20\% QC composite consolidated by different number of turns of HPT.
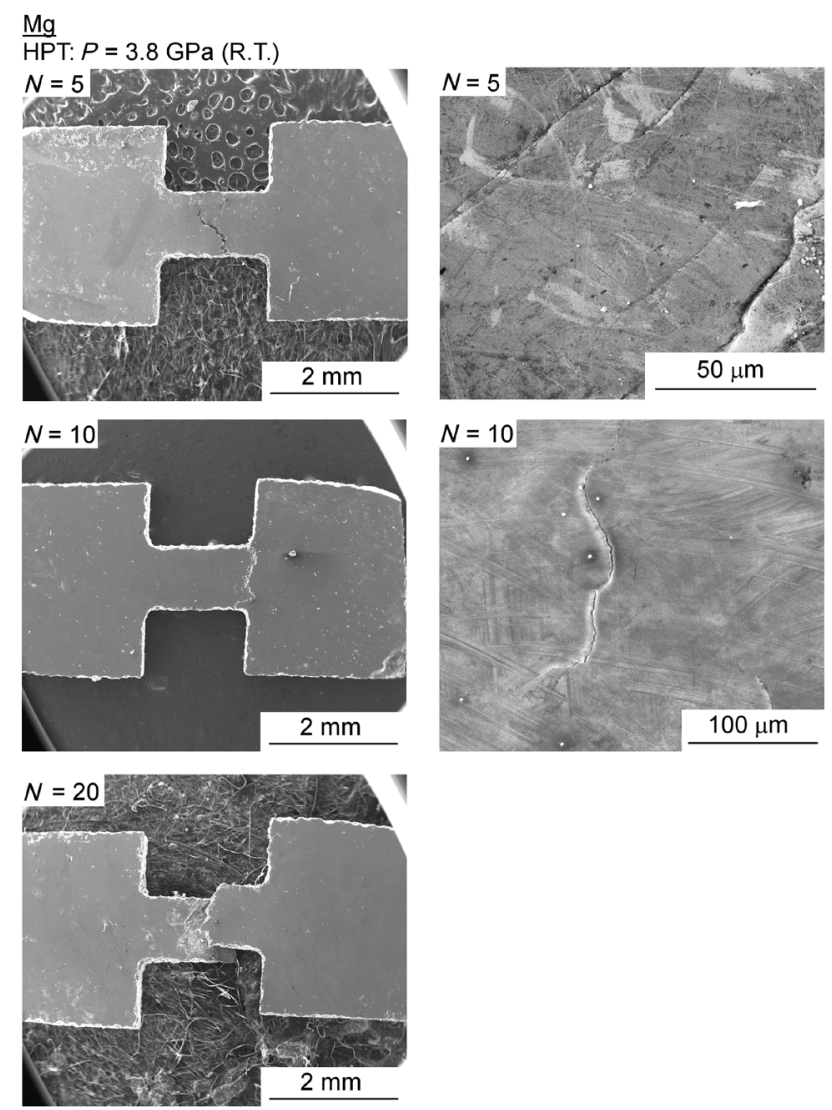

Fig. 4. Representative images of the tensile specimens of pure magnesium consolidated by HPT and tested to failure.
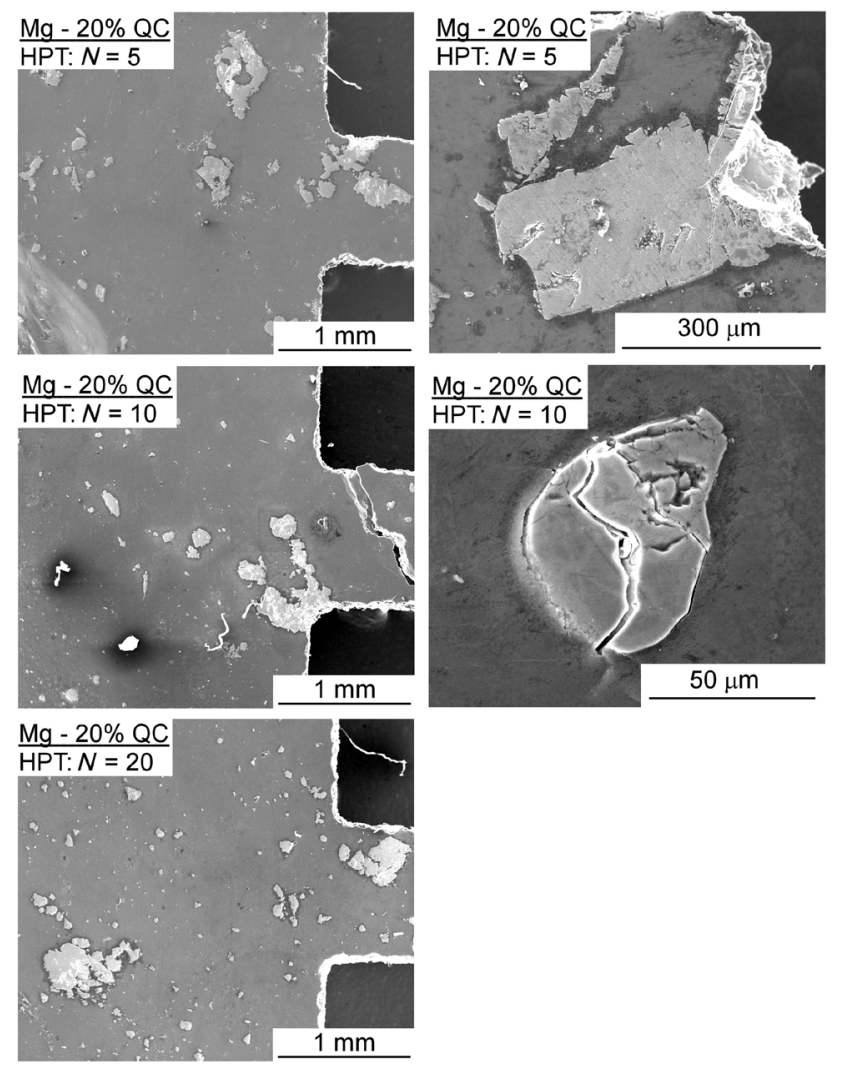

Fig. 5. Representative images of the tensile specimens of $\mathrm{Mg}-20 \%$ QC composite consolidated by HPT and tested to failure. 
with the almost brittle behavior observed in the stress-strain curves. Slip bands were observed in different locations of the gauge length which shows a high tendency for localized deformation. Also, cracks were observed in areas far from the rupture surface. These cracks did not develop due to the reduced deformation but they confirm that consolidation was not complete.

The specimens of Mg-20\% QC composite contained some QC particles with sizes over $100 \mu \mathrm{m}$ within the gauge length. The images on the left-hand side of Fig. 5 show the area of the specimen's head where a gradual decrease in the size of the QC particles with increasing the number of turns is observed. These particles could nucleate cracks. For instance, the image on the top right shows a coarse QC particle in the fracture tip of the specimen. Also, cracking of the QC particles and a lack of continuity of these particles with the magnesium matrix were observed. The image on the right-side, for $N=10$, shows an evidence of both. These could nucleate cracks and reduce the tensile ductility of the composite which agrees with the low elongations observed in tensile tests.

\section{Discussion}

The consolidation of metallic particles through HPT requires a high pressure to promote plastic deformation and full contact between the particles and high shear strain to break up the oxide surface layer and promote chemical bonding between the metals. Thus, it is expected that hard materials will have a difficulty to be consolidated due to the increased resistance against plastic deformation. Also, the thickness and resistance of the oxide layer is expected to affect the consolidation. The present results confirm that the AZ91 alloy is difficult to consolidate in comparison with pure magnesium. Composites with similar amount of hard quasicrystal particles could be consolidated by 10 turns of HPT using pure magnesium as matrix material but not with AZ91. It is worth noting that previous studies have shown that pure magnesium chips, pure or with the addition of alumina particles, could be consolidated after 5 turns of HPT $[11,16]$. On the other hand, machining chips of AZ91 were not consolidated in the same conditions [16]. Also, a recent paper showed the lack of consolidation of an AZ91-Bioactive Glass composite even after 50 turns of HPT [13].

Furthermore, the present results suggest that consolidation is not completed in pure magnesium discs and $\mathrm{Mg}-20 \%$ QC composite. This can be attributed to the heterogeneity of plastic deformation during HPT processing of magnesium [25-27]. Thus, some volumes of the sample might not undergo sufficient shear straining to promote bonding between the particles. Areas with the lack of consolidation can act as pre-existent cracks in the processed discs and compromise the tensile ductility of the material as shown in the present tensile tests. This explains the limited elongations observed in all samples of pure magnesium and Mg-20\% QC composite.

\section{Summary and conclusions}

1. Commercial purity magnesium and the AZ91 alloy particles were mixed with quasicrystal particles and processed by HPT. The processed discs were observed in SEM. Tensile tests were carried out in the $\mathrm{Mg}$-QC composite and in samples of pure magnesium particles processed by HPT.

2. SEM images show significant consolidation of pure magnesium with quasicrystal particles and general lack of consolidation when using the AZ91 alloy as matrix material.

3. Pure magnesium consolidated by HPT display higher strength but reduced ductility compared to bulk pure magnesium processed by HPT. The brittle behavior is attributed to pre-existing cracks due to localized lack of bonding.

4. Mg-20\% QC composite processed to 10 turns display high strength but limited ductility. The limited ductility is attributed to cracking of the coarse quasicrystal particles and lack of bonding between the reinforcement phase and the matrix.

Acknowledgements. RBF acknowledges financial support from CNPq (grant \#400407/2016-7), FAPEMIG (grant \#APQ-00580-15) and Serrapilheira Institute (grant \#Serra1709-17750). MMC received a research fellowship from CAPES.

\section{References}

1. H. Asgharzadeh, S.-H. Joo, J.-K. Lee, H. S. Kim. Journal of Materials Science. 50, 3164 (2015). Crossref

2. M. Ashida, Z. Horita, T. Kita, A. Kato. Materials Transactions. 53, 13 (2012). Crossref

3. W. Xu, X. Wu, T. Honma, S.P. Ringer, K. Xia. Acta Materialia. 57, 4321 (2009). Crossref

4. A. P. Zhilyaev, A. A. Gimazov, G.I. Raab, T. G. Langdon. Materials Science and Engineering: A. 486, 123 (2008). Crossref

5. W.J. Botta Filho, J.B. Fogagnolo, C.A.D. Rodrigues, C.S. Kiminami, C. Bolfarini, A.R. Yavari. Materials Science and Engineering: A. 375-377, 936 (2004). Crossref

6. Z. Lee, F. Zhou, R.Z. Valiev, E. J. Lavernia, S. R. Nutt. Scripta Materialia. 51, 209 (2004). Crossref

7. I. V. Alexandrov, Y. T. Zhu, T.C. Lowe, R. K. Islamgaliev, R.Z. Valiev. Nanostructured Materials. 10, 45 (1998). Crossref

8. I. V. Alexandrov, R. K. Islamgaliev, R.Z. Valiev, Y.T. Zhu, T.C. Lowe. Metallurgical and Materials Transactions A. 29, 2253 (1998). Crossref

9. R. B. Figueiredo, T.G. Langdon. Advanced Engineering Materials. 21, 1801039 (2019). Crossref

10. A.P. Zhilyaev, T.G. Langdon. Progress in Materials Science. 53, 893 (2008). $\underline{\text { Crossref }}$

11. M. M. Castro, P.H. R. Pereira, A. Isaac, R. B. Figueiredo, T. G. Langdon. Journal of Alloys and Compounds. 780, 422 (2019). Crossref

12. M.M.Castro, S. Sabbaghianrad, P.H. R. Pereira, E. M. Mazzer, A. Isaac, T.G. Langdon, R. B. Figueiredo. Journal of Alloys and Compounds. 804, 421 (2019). Crossref

13. M.M. Castro, D. R. Lopes, R. B. Soares, D. M. M. dos Santos, E.H. M. Nunes, V.F. C. Lins, P.H. R. Pereira, A. Isaac, T. G. Langdon, R. B. Figueiredo. Materials. 12, 2609 (2019). Crossref

14. R. B. Figueiredo, S. Sabbaghianrad, A. Giwa, J. R. Greer, T. G. Langdon. Acta Materialia. 122, 322 (2017). $\underline{\text { Crossref }}$ 
15. E. Y. Yoon, D. J. Lee, T.S. Kim, H. J. Chae, P. Jenei, J. Gubicza, T. Ungar, M. Janecek, J. Vratna, S. Lee, H.S. Kim. Journal of Materials Science. 47, 7117 (2012). Crossref

16. M. M. de Castro, A. P. Carvalho, P. H. R. Pereira, A. C. Isaac Neta, R. B. Figueiredo, T. G. Langdon. Materials Science Forum. 941, 851 (2019). Crossref

17. J.-M. Dubois. Materials Science and Engineering: A. $294-296,4$ (2000). Crossref

18. B.A. Silva Guedes de Lima, R. Medeiros Gomes, S. J. Guedes de Lima, D. Dragoe, M.-G. BarthesLabrousse, R. Kouitat-Njiwa, J.-M. Dubois. Science and Technology of Advanced Materials. 17, 71 (2016). Crossref

19. J.-M. Dubois. Chemical Society Reviews. 41, 6760 (2012). Crossref

20. M. Galano, F. Audebert, I.C. Stone, B. Cantor. Acta Materialia. 57, 5107 (2009). $\underline{\text { Crossref }}$
21. W. Wolf, C. Bolfarini, C. S. Kiminami, W. J. Botta. Scripta Materialia. 173, 21 (2019). Crossref

22. W. Wolf, L.C.R. Aliaga, D. N. Travessa, C. R. M. Afonso, C. Bolfarini, C.S. Kiminami, W. J. Botta. Materials Research. 19, 74 (2016). Crossref

23. R. B. Figueiredo, S. Sabbaghianrad, T.G. Langdon. IOP Conference Series: Materials Science and Engineering. 194, 012039 (2017). Crossref

24. R. B. Figueiredo, P. H. R. Pereira, T. G. Langdon. Advanced Engineering Materials. 0, 1900565 (2019). Crossref

25. R. B. Figueiredo, M. Kawasaki, T.G. Langdon. Acta Physica Polonica A. 122, 425 (2012). Crossref

26. R. B. Figueiredo, M.T. P. Aguilar, P.R. Cetlin, T. G. Langdon. Metallurgical and Materials Transactions A: Physical Metallurgy and Materials Science. 42, 3013 (2011). Crossref

27. R.B. Figueiredo, T.G. Langdon. Materials Science and Engineering A. 528, 4500 (2011). $\underline{\text { Crossref }}$ 